\title{
Lessons learned from library mergers at colleges of higher education in Flanders
}

\author{
Adriaan Swanepoel ${ }^{\prime}$ \\ Library and Information Services (Pretoria Campus)Tshwane University of Technology, \\ Private Bag X680, Pretoria 000I, South Africa \\ swanepoelaj@tut.ac.za
}

\begin{abstract}
Received: $5^{\text {th }}$ March 2004
Revised: $17^{\text {th }}$ August 2004

This article reports the findings of an investigation into merger experiences of several libraries of colleges of higher education in Flanders. The purpose of the study was to gain first hand knowledge from institutions who recently merged; especially, what best practices to follow and what to avoid. Data was gathered with a mail questionnaire and followed by personal interviews with the heads of the selected libraries concerned. The article includes topics such as the composition and tasks of merger task teams, most difficult issues in the planning phase, the role of consultants, how progress is monitored and communicated, dealing with different organisational cultures, decisions that have an impact on merger outcomes, appointment of a post-merger library head, duration of a merger, do's and don'ts, outcomes of library mergers, and challenges of library mergers. It is concluded with a list of lessons that other libraries can learn from the Flemish experience and indicates whether a particular lesson is supported by the merger literature or not.
\end{abstract}

Keywords: Library mergers; College libraries; Flemish libraries

\section{Introduction}

In 2002, when South Africa's Minister of Education announced the mergers of several institutions of higher education (South Africa, 2002), many people were faced with a totally new and unfamiliar task. That was also the case with the people involved in merging the libraries of those institutions. To those who had access to the Ministry of Education's official Guidelines for Mergers and Incorporations (South Africa, 2003), the challenge of merging libraries of different institutions was somewhat less daunting, since that document maps out the essentials, the generic tasks and processes of mergers. However, librarians still had to look elsewhere for information if they wanted to learn how other libraries performed their mergers, and, especially, what best practices to follow and what to avoid.

A literature survey will show that, even though mergers in higher education are not too uncommon, and have resulted in several reports and research publications, the merger literature contains little information on the theory or practice of library mergers in higher education. Reasons for the scarcity of such information are not clear, but it could be due to the fact that most libraries never become involved in a merger, and if they do experience a merger, it is most unlikely that such an event would occur more than once in a librarian's term of office. The first journal article on the topic from a South African perspective appeared only as recently as 2003 (Jayaram, 2003) and although it gives a good overview of the merger process between the libraries of the former ML Sultan Technikon and Technikon Natal, there is a need for additional case studies that will guide libraries of higher education institutions through a process that Burckhardt (1994:19) describes as follows: 'Higher education mergers are not a bold collision of magnates. They are nervous, protracted affairs requiring a special courage, deep pragmatism, and many sensitive deliberations.'

The purpose of this article is to make a contribution to the research literature on library mergers in higher education by (a) presenting and discussing the results of a case study that explored the mergers of several libraries at colleges of higher education in Flanders, and (b) to indicate what lessons other librarians could learn from the Flemish experience.

\section{Methodology and research procedure}

In order to gain firsthand knowledge of the subject of library mergers, the author visited a number of libraries at selected colleges of higher education in Flanders, in March 2003. The study was not intended to be comprehensive but to learn from the everyday experiences, including the good and bad practices, of libraries that were recently involved in a merger. The purpose was furthermore to determine whether the practicalities of library mergers corresponded to merger theory, in general.

I. Dr A.J. Swanepoel is Acting Director: Library and Information Services (Pretoria Campus)Tshwane University of Technology, South Africa 
There were three reasons for selecting the libraries of colleges of higher education in Flanders as a source of information'. Firstly, some of the libraries had merged only recently, while others were still in the process of merging. The author was of the opinion that would lead to more accurate and reliable information, since it was assumed that the merger process and experiences would still be fresh in the minds of the library staff concerned. Secondly, the author wanted to select libraries of institutions that compared well with libraries of technikons in South Africa in terms of the type of institutions that they serve. The third reason was of a more practical nature. Due to limited time and finances, the author had to select a sample whereby the largest number of higher education institutions could be visited and studied in the shortest space of time. Eventually, the libraries of eight different post-merger institutions situated in six different cities in Flanders were identified. According to Verhoeven et al. (2002:I) there were twenty-four colleges of higher education in Flanders in the 200I - 2002 academic year. Although the eight libraries concerned were not selected according to scientific sampling procedures, they all met the criteria outlined above. Although the purpose of the study was not necessarily to get a fully representative picture of library mergers in Flemish colleges of higher education, the selected libraries were nevertheless representative of a wider population in several ways: Three of the libraries were attached to Catholic institutions and five were autonomous institutions; they all offered a wide range of disciplines and courses; each institution was the result of a merger of four or more pre-merger institutions; the eight institutions represented $33.3 \%$ of the total colleges of higher education in Flanders in 2002, and each of the eight institutions was regarded as being of note in the Flemish higher education system.

Prior to a trip to the selected libraries, the author sent each of the library directors/heads a questionnaire ${ }^{2}$ containing thirteen structured and twenty unstructured questions. The structured questions were designed to obtain fixedalternative responses as well as scaled responses. Questions were classified under the following headings: pre-merger planning, merger implementation, outcomes and post-merger activities. Some of the library heads completed and returned the questionnaire by mail, while others returned it on the day of the visit. On the day of an appointment, the author interviewed the library head, but concentrated primarily on those questions and answers in the questionnaire that needed further explanation or clarification - either by the author or the persons who completed the questionnaires. Back home in South Africa, the author analysed the answers and made conclusions. The findings of the questionnaire and the conclusions are presented in this article

\section{Findings}

\subsection{Composition and tasks of merger task teams}

Apart from preparations made at an institutional level, seven of the eight libraries used separate task teams or committees to help plan their respective library mergers. All of the task teams included the heads of participating libraries. Only four of the teams included other members of participating libraries. At three of the libraries, the merger tasks teams also consisted of members of their respective institutions' merger task teams, while at two libraries the task teams also involved colleagues from other libraries. One of the teams also had a consultant as a member. None of the libraries involved students, academic staff or trade union members in their merger tasks teams.

Not surprisingly, the tasks of the respective library merger task teams were largely determined by the demands and needs resulting from the mergers. For instance, in one case, where a new library had to be designed and built, that aspect dominated the agenda of the library's merger task team. In two other cases, a new library computer system had to be implemented and that, in turn, constituted the main task of the respective merger task teams. It was also noticeable that there was no core or standard list of tasks used by all of the task teams. The list of tasks that follows is therefore not representative, but it nevertheless gives an indication of the variety of tasks that were performed by the merger task teams of the eight libraries: formulating new strategies and goals, formulating a new organisational model, integrating library collections, assigning (new) tasks to library staff, planning a new library building, redesigning existing libraries, creating a new central library, formulating uniform library rules and regulations, improving infrastructure, changing library procedures, and formulating uniform administrative procedures.

I. When the author planned his research in January 2003, he also wanted to use the library merger experiences of the Durban Institute of Technology (DIT) as a local source of information. DIT came into being on I April 2002 as a result of a merger between ML Sultan Technikon and Technikon Natal, and was one of the first of the higher institutions in South Africa to have merged in recent times. Therefore, information on DIT's library merger experience would have been valuable input to the author's study. Unfortunately DIT's library did not return the author's questionnaire. However, since then an article by Jayaram (2003) on the merger process between the libraries of ML Sultan and Technikon Natal has appeared in South African Journal of Libraries and Information Science.

2. The author will gladly furnish details of the questionnaire to anyone wishing further information. 
3.2. Most difficult issues in the planning phase

The library heads all gave different answers to an open-ended question on what the most difficult issues were during the planning of the merger.

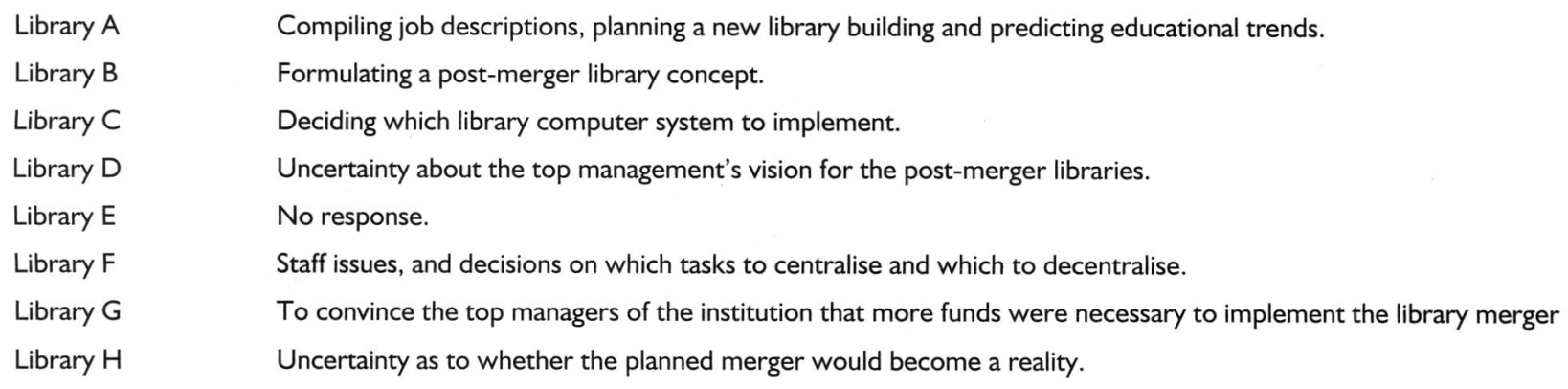

\subsection{The role of consultants in the merger process}

Diverse answers were given when the respondents were asked how important it was to have the services of an independent consultant, regardless of whether or not independent consultants were part of a library's merger task team. Three respondents indicated that they do not regard the services of a consultant important; two respondents regarded such services as somewhat important, while three said they were important. None of the respondents regarded the services of an independent consultant as crucial.

The respondents answered as follows when asked what tasks and responsibilities they would allocate to an independent consultant if they had an opportunity to appoint one:

- Assisting with the planning of new library building.

- Providing guidance with the merger process.

- Presenting an objective vision for the library.

- Giving advice with regard to the reallocation of library collections.

- Doing an objective and neutral survey of the libraries involved.

- Determining the needs of library users and planning how to optimise the new library's services to all users.

- Identifying a suitable integrated library system for the new library service.

- Reconciling the merger strategy of participating libraries with the merger strategy of the institution.

- Giving advice on how to determine a merger strategy.

- Identifying problems.

- Identifying best practices.

- Acting as neutral chairperson of the merger task team.

The above list is informative, since it probably gives an indication of the tasks that the library heads found difficult to perform themselves, and with which they would have preferred to have assistance.

\subsection{How progress was monitored and communicated}

The libraries concerned communicated progress with the merger process mainly in the following ways: verbal reports at meetings of their library merger task teams and written and verbal reports to the top managers of their institutions.

Not all the respondents gave clear answers on how they had monitored the progress with the implementation of the merger. However, one library used a pre-set time schedule, while another library measured the process by way of a questionnaire and the results of a SWOT analysis.

\subsection{Dealing with different organisational cultures}

The library heads indicated that mergers at their respective libraries had not been affected much by different organisational cultures. At all of the post-merger libraries the tasks, procedures and organisational cultures remained very much the same as before the merger. One of the respondents even indicated that, in a sense, no merger had taken place. However, even though the differences in organisational cultures were minimal, two of the libraries found it necessary to take deliberate steps to manage those differences. At one of the libraries, cultural differences were discussed at staff meetings, and staff used the opportunity to propose solutions. Another library not only organised team-building exercises, but the head of the library also had discussions with individual staff members to explain their tasks and responsibilities and to measure job satisfaction.

3.6. Decisions that had the biggest impact on the outcomes of mergers

The library heads were asked what decisions had the biggest impact on the outcomes of their libraries' mergers. Their answers are summarised in five categories:

- Decisions that had to do with physical facilities (three respondents). 
- Decisions that had to do with the library's organisational model (five respondents).

- Decisions that had to do with policy and procedures (five respondents).

- Decisions that had to do with staff issues (three respondents).

- Decisions that had to do with selecting a new library computer system (three respondents).

3.7. Appointment of a post-merger library head

The library heads were asked the following questions regarding leadership issues: (a) Was an interim library head appointed during the merger process? (b) When (at what stage of the merger process) was a single (permanent) library head appointed? (c) How was the appointment of the new library head decided on? (d) What happened to those head(s) of pre-merger libraries who were not appointed head of the new merged library?

The answers to the questions above not only showed similarities in the way that libraries dealt with leadership issues, but they also highlighted some subtle differences. A practice that was common at most of the libraries was to appoint a post-merger library head from the ranks of the pre-merger library heads. At two of the institutions, the pre-merger library heads could apply for the post of post-merger library head, but at the other six institutions the post-merger library heads were merely appointed by the top managers of the respective institutions. Another common practice at six of the institutions was that pre-merger library heads who had not been appointed heads of new (post-merger) libraries remained in their previous jobs. However, there were two exceptions to this practice: At one institution, an interim library head was appointed from the ranks of participating libraries, but after several months no permanent appointment had yet been made. At another institution, two heads of two pre-merger libraries were jointly responsible for library leadership at the new post-merger library.

\subsection{Duration of the merger}

Two of the respondents indicated that it took less than two years to implement the mergers at their respective libraries, while four of the respondents said the implementation phase lasted more than three years. The remaining two respondents indicated that the question on the duration of the merger was not applicable to their respective libraries. The reason was that the merger at one of the libraries was still in progress at the time of the survey, while in the other case the respondent indicated that although a merger had taken place at an institutional level, the situation of the respective libraries remained more or less unchanged.

Of the six libraries who responded to the question, four indicated that the implementation process would have taken less time, if it had not been for various factors that delayed the process. Those factors differed from library to library and included the following: Planning a new library building, insufficient library staff, the inclusion of yet another library in the merger process, large-scale alterations to existing library buildings, insufficient control of merger activities, insufficient funding, human factors, and delays caused by information technology problems.

\subsection{What respondents would do differently next time}

Five of the eight respondents said they would go about things differently if they had to plan and implement the merger again. The things that they would do differently are listed below.

- Obtain bigger participation from academic staff and students in the planning process (two respondents).

- Speed up the implementation process.

- Obtain better control over merger activities.

- Try to be better prepared for possible problem areas.

- Speed up decision-making processes.

- Start with systematic preparation right from the start of the merger.

\subsection{Do's and don'ts}

Apart from things that they would do differently next time, the respondents also gave the following advice on what should be done during a library merger and what should not be done:

Do's:

- Plan the merger thoroughly.

- Communicate merger issues regularly with your staff.

- Listen to the opinions and concerns of your staff. Encourage them to make suggestions.

- Involve all stakeholders right from the beginning of the merger.

- Act in good time when problems occur. Do not let things get out of hand.

- Ensure that the library merger is in harmony with developments inside and outside the institution and that all stakeholders (students, academic staff, top management, etc.) support the aims of the library merger.

- If possible, ensure that the top management of the institution supports the vision of the library.

- Compile a clear organisational model for the library.

- Ensure that the tasks and responsibilities of the post-merger library staff members are clearly defined. 
- As far as possible, implement uniform library rules and regulations for all participating libraries.

- Give equal consideration to the needs of all library users and avoid granting favours to members of a particular premerger group.

- Re-evaluate implementation plans regularly.

- Be positive about the merger

Don'ts:

- Heads of libraries and merger task teams should not focus on detail.

- Unless it is necessary, library heads and merger task teams should not become involved with specialist matters such as indexing or classification, but should rather leave that to the subject specialist.

- Don't start too many merger processes at the same time.

- Don't try to organise all by yourself.

- Don't give instructions without proper consultation with relevant stakeholders.

- When a merger necessitates a new library computer system, don't develop an in-house computer system, but rather get advice and buy a system that meets the needs of the institution.

3.11. Outcomes of library mergers

The questionnaire contained various questions about the results and outcomes of library mergers. In one of the questions, respondents had to indicate to what extent they agreed with certain statements. The results are summarised in Table I.

Table I Outcomes of library mergers

\begin{tabular}{|c|c|c|c|c|}
\hline Outcomes of library mergers & Do not agree & $\begin{array}{l}\text { Agree to a } \\
\text { certain extent }\end{array}$ & Fully agree & $\mathrm{N}$ \\
\hline The post-merger library serves academic goals and activities better than before & 0 & I & 6 & 7 \\
\hline The quality of library service has increased & 0 & 3 & 4 & 7 \\
\hline The post-merger library maintains the same level of service as the pre-merger libraries & 0 & 7 & 0 & 7 \\
\hline The merger was beneficial to one or more of the pre-merger libraries & I & I & 5 & 7 \\
\hline The post-merger library has acquired additional tasks and units & 0 & 0 & 7 & 7 \\
\hline Operations in the post-merger library have become more complex & 0 & 3 & 5 & 8 \\
\hline After the merger it was business as usual & 5 & 2 & I & 8 \\
\hline
\end{tabular}

Although the mergers resulted in positive changes at seven of the libraries, some changes were negative. Not only did the mergers bring about additional tasks and units, but operations also became more complex. In this context, it is surprising that three of the respondents indicated that it was "business as usual" after the merger.

It is necessary to give some clarification regarding the answers of those respondents who indicated that it was "business as usual" after the merger. The respondent who fully agreed with the statement also replied to some of the other questions that, although a merger took place at an institutional level, the situation of the participating libraries remained more or less the same. This also explains why some of the questions were answered by seven respondents only, instead of eight. The two respondents who only agreed to some extent that it was business as usual after the merger, probably referred to the situations at their respective libraries where some of the services, facilities and procedures remained the same as before the merger.

In reply to an open-ended question, the respondents also added several other positive and negative or disappointing outcomes of the their respective library mergers. It is noticeable that there was more agreement between respondents regarding negative outcomes.

Positive outcomes

- Obtaining a new library building.

- Cooperation with other (new) colleagues and the opportunity to participate in new tasks and responsibilities (two respondents).

- Opportunity to specialise (in a bigger library set-up) (two respondents).

- Improvement of library management and administration.

- Library users have access to more information sources.

- Obtaining a new integrated library computer system (three respondents).

- Computerising the loans processes.

- Obtaining an electromagnetic system to protect the library's information sources. 
- Obtaining more finances.

- Obtaining more library staff.

- Subscribing to more electronic databases.

- Improvement of library infrastructure.

- Improved visibility/prominence in the Flemish library community.

- Bigger opportunity to utilise information technology.

- Able to render more services (two respondents).

- Improvement of library services.

- Increased professionalism.

Negative or disappointing outcomes

- After the merger some of the library staff had less contact with library users, because they no longer worked in small, one-person libraries. Coupled with this was a loss of independence (four respondents).

- The merger resulted in more work at managerial and administrative levels (four respondents).

- The merger brought together different organisational cultures that were difficult to reconcile.

- Implementing the merger was an ungrateful task.

Respondents were also asked whether the merger had led to savings. From their answers (see Table 2) it seems that few savings occurred. As a matter of fact, four of the eight respondents elucidated their response by saying that the merger at their respective libraries led to increased costs in many respects.

Table 2 Savings as a result of the merger

\begin{tabular}{|c|c|c|c|c|}
\hline Savings as a result of the merger & No & Unsure & Too early to tell & Yes \\
\hline Staff reductions & 7 & 0 & 0 & 1 \\
\hline Reduced capital budget & 7 & 0 & 1 & 0 \\
\hline Reduced operational budget & 7 & 0 & । & 0 \\
\hline Cancellation of journal subscriptions & 2 & 0 & 0 & 6 \\
\hline Economies of scale & I & 3 & 1 & 3 \\
\hline Fewer library buildings & 4 & 2 & 0 & 2 \\
\hline Changes in library services & 5 & । & 0 & 2 \\
\hline
\end{tabular}

It is clear from Table 2 that savings due to the cancellation of (duplicate) journal subscriptions occurred at most (six) of the institutions. Three of the respondents could also agree with certainty that the merger had resulted in economies of scale. Otherwise it seems that the mergers resulted in no or few savings as far as the libraries are concerned.

\subsection{Challenges}

Table 3 gives an indication of how challenging the library mergers were to the library heads. From the findings it seems that dealing with staff issues was considered the most challenging aspect of a merger.

Table 3 Merger issues considered to be challenging

\begin{tabular}{|c|c|c|c|c|}
\hline Merger issues considered to be challenging & Not challenging & Somewhat challenging & Very challenging & Not applicable \\
\hline Planning the merger & 0 & 3 & 4 & I \\
\hline Dealing with staff issues & 0 & 2 & 5 & I \\
\hline Implementing the merger & 0 & 2 & 5 & I \\
\hline Keeping stakeholders informed & 2 & 5 & 0 & । \\
\hline Managing different organisational cultures & I & 5 & 2 & 0 \\
\hline Library name changes & 2 & 3 & 0 & 3 \\
\hline Leadership issues & 2 & 4 & 1 & I \\
\hline Integrating library collections & 1 & 3 & 3 & 1 \\
\hline Managing post-merger issues & 0 & 2 & 4 & 2 \\
\hline Other & 0 & 0 & 0 & 0 \\
\hline
\end{tabular}




\section{Lessons learned}

Although the libraries visited were smaller than their South African counterparts in terms of collections, staff and users, most of their experiences regarding library mergers are of such a general nature that they can be applied to small and large libraries of higher education alike.

The lessons listed below are merely an effort to summarise some of the findings of this study, and readers will probably find many other lessons applicable to their particular situations in par. 3.9 to 3.12 of this article.

Lesson I. Library mergers at institutions of higher education should not be underestimated in terms of complexity and the volume of work involved. Even relatively small libraries, such as the college libraries whose experiences are described in this article, have shown that the task of merging libraries is not merely about integrating information sources, staff, facilities and budgets. Library mergers may also involve planning new or additional facilities (e.g., new library buildings), changing or upgrading to new computer systems, changing from a decentralised to a centralised organisation or vice versa, managing different organisational cultures and changing library rules, policies, procedures and standards. Under normal (non-merger) circumstances, a library would probably only plan and implement one or a few of these activities at a time. However, the experiences of the Flemish college libraries have shown that, in most of the cases, library managers had to deal simultaneously with a number of these demanding tasks. Library managers who participate in a merger can therefore expect that a merger will make extraordinary demands on their project-planning skills and capabilities.

The findings that led to this lesson were not totally unexpected. In one of the few scholarly publications on library mergers in higher education, Sacks (1994:169) states: "Mergers involve an enormous amount of adjustment to change in a dramatically short period of time. There are limits to the amount and rate of change library staff members may be able to assimilate". In another publication, not referring to libraries but equally applicable to them, the Further Education Funding Council (FEFC) gives the following warning: "It cannot be over-emphasised that institutional merger is a complex and time-consuming process. The work associated with the achievement of a merger should never be underestimated. The merger process involves extensive commitment of senior staff time, and must be organised to ensure that the service to existing customers and clients does not suffer during the process" (FEFC: 1998:4).

Lesson 2. It would be to the advantage of library managers to involve independent consultants. The survey identified a variety of tasks whereby a consultant could assist library managers or merger task teams (see par. 3.3) and in doing so relieve some of the burdens caused by merger demands. Independent consultants can also be invaluable when library managers and tasks teams lack the necessary skills and knowledge to perform merger-related tasks. This corresponds with the views by Dougherty and McClure (2000:5) in an article on the merging of libraries with computing centres at institutions of higher education.

Lesson 3. Even in circumstances where the organisational cultures of merging libraries differ only marginally, it may still necessitate deliberate actions to manage those differences (see 3.5). This is in line with the overall sentiment in the merger literature that emphasises the importance of (a) understanding organisational cultures and (b) managing different corporate cultures effectively. A number of writers even consider the ability of merging partners to adjust to a new organisational culture as one of the conditions for merger success (Hirshon, 1998:9; McKnight, 2002: 10; Walker \& Price, 2000:4). This emphasis on organisational culture issues is understandable when considering Harman's statement that 'Cultural conflict has proved to be the norm in the post-merger phase of most institutions' (Harman, 2002:108).

Lesson 4. Library mergers do not necessarily follow the paths or the time schedules that were initially planned. This survey has shown that circumstances beyond the control of libraries could result in major delays during a merger (see par 3.8).

Lesson 5. It is unlikely that there will be a second time to do it right. In this survey, the respondents indicated a number of things that they would do differently if they had to plan and implement the merger all over again (see par. 3.9). The reality is that mergers seldom occur more than once in a librarian's term of office. It is therefore imperative that people involved in library mergers ensure that they do it right the first time round.

Lesson 6. In the list of do's and don'ts given by the respondents (see par 3.10), three issues or themes were stressed over and again. The first is to plan the merger thoroughly. The second is effective and regular communication to all stakeholders. The third issue is to focus on the vision of the merger and to refrain from becoming too involved in detail. Not surprisingly, these three themes are among the ones that are often highlighted in the merger literature (Appelbaum, et al, 2000:658; Lucenko, 1999: 8 - 24).

Lesson 7. From the experiences of the colleges participating in this survey, it is clear that library mergers could lead to wide-ranging positive outcomes, including benefits to the library, the institution and the wider library community (see par 3. II). However, one should be aware that such positive outcomes could come with a price, for instance, an increase 
in the complexity and volume of work, a loss of independence and an even more complex organisational structure (see par 3.1I).

Lesson 8. Smaller partners in a library merger can benefit greatly in a merger, since they become part of a bigger setup with more or sometimes better facilities, infrastructure and resources (see also lesson 7).

Lesson 9. Library mergers at institutions of higher education do not necessarily lead to savings (see Table 2). This is contrary to what is sometimes assumed by the initiators of mergers (Huang, 2000:23). It also seems, from the experiences of the Flemish colleges, that savings in one area (e.g. savings due to the cancellation of duplicate journal subscriptions) are often cancelled by increased expenditures in another area (e.g. increases in capital expenditure). In a study of library mergers at two Australian universities, Gamage (1992:85) reported a similar phenomenon.

Lesson 10. There is no uniform way of merging libraries at institutions of higher education. Although there were noticeable similarities between the types of merger challenges and problems that libraries in this survey experienced, they did not all react in the same way to those challenges and problems, but nevertheless managed to succeed.

\section{Conclusions}

The author found the experiences shared by librarians in this study to be of great value. Not only did they provide sound practical advice on what steps other librarians could follow in similar situations, but their combined experiences also provided lessons of a more general nature that can be applied to small and large libraries alike. If the lessons that are contained in this article could be verified and complemented by lessons learned from other library mergers, it could make a valuable contribution to a library merger theory.

The author also found that most of the lessons learned from the merger experiences of the eight libraries under investigation are supported by the views and experiences of others - either in the corporate or in the higher education environment.

\section{Acknowledgment}

The author is grateful to the LIASA Trust, who sponsored his study visit to Flanders.

\section{References}

Appelbaum, Steven H. et al. 2000. Anatomy of a merger: behavior of organizational factors and processes throughout the preduring- and post- stages (part I), Management Decision, 38(9): 649 - 66I.

Burkhardt, John. 2003. Getting to yes on a merger, Planning for Higher Education, 22(3): 19 - 24.

Dougherty, Richard M. \& McClure, Lisa. 2000. Repositioning campus information units for the era of digital libraries. [Online]: http://www.ala.org/acrl/pil/dougherty.html. Accessed: 27 August 2002.

Further Education Funding Council. 1998. The financial benefits of mergers of Further Education Colleges. Coventry: FEFC. (A FEFC Report).

Gamage, D.T. 1992. La Trobe and Lincoln Merger: The Process and Outcome. Journal of Educational Administration, 30(4): 73 89.

Harman, Kay. 2002. Merging divergent campus cultures into coherent educational communities: Challenges for higher education leaders. Higher Education, 44(I): 91 - 114.

Hirshon, Arnold. 1998. Integrating computing and library services: an administrative planning and implementation guide for information resources. Boulder, Colorado: CAUSE. (CAUSE Professional Paper Series \# 18). [Online]: http://www.cause.org Accessed: 27 August 2002.

Huang, Hong-Wei. 2000. College and university mergers: impact on academic libraries in China. College \& Research Libraries, March, $121-125$.

Jayaram, Veena. 2003. The merger process between libraries of ML Sultan and Technikon Natal: reflections of a practitioner. South African Journal of Libraries and Information Science, 69(I): 84-9I.

Lucenko, Kristina. 1999. Implementing a post-merger integration. New York: The Conference Board Inc.

McKnight, Sue. 2002. Managing cultural change: the challenge of merging library services, curriculum development and academic professional development. Paper presented at the 68 $8^{\text {th }}$ IFLA Conference, Glasgow, Scotland. August 2002. [Online]: http:// ifla.org Accessed: 4 December 2002.

Sacks, Patricia. 1994. Consolidating library collection and learning-resource technologies, in: Martin, James \& Samels James E. 1994. Merging colleges for mutual growth: a new strategy for academic managers. Baltimore: John Hopkins University Press.

South Africa. Ministry of Education. 2002. Transformation and Restructuring: A New Institutional Landscape for Higher Education.

South Africa. Ministry of Education. 2004. Higher education restructuring and transformation: Guidelines for mergers and incorporations. 118p.

Verhoeven, J.C. et al. 2002. Hogescholen enkele jaren na de fusie. Antwerpen: Garant.

Walker, James W. \& Price, Karl F. 2000. Why do mergers go RIGHT? [Online]: http://www.walkergroup.com/docs/Mergers.doc Accessed: 4 December 2002. 